\title{
Ningún lugar está lejos cuando se ama
}

\author{
Mónica Pilar Cobaleda Estepa
}

\section{Resumen}

Este testimonio fue escrito bajo la premisa de compartir la experiencias de enseñanza en época de pandemia. En él se relata la vivencia en el trabajo en segundo grado de básica primaria, en una institución pública de la ciudad de Medellín-Colombia.

Palabras clave: resiliencia, alegría, empatía, vocación, amor.

\section{NO PLACE IS FAR WHEN YOU LOVE}

\section{Abstract}

This testimony was written under the premise of sharing teaching experiences in times of pandemic. It relates an experience in the second grade of elementary school, in a public institution in the city of Medellín-Colombia.

Keywords: resilience, joy, empathy, vocation, love. 
"Ningún lugar está lejos cuando se ama"

Mónica Pilar Cobaleda Estepa

Vol. 22, Núm. 1, enero-febrero 2021

Revista Digital Universitaria

\section{Mónica Pilar Cobaleda Estepa}

monicacobaleda@gmail.com

orcid.org/0000-0003-1863-598X

Instagram: @colombia.de.colores

Docente en la Institución Educativa Jorge Robledo - IEJR, Medellín, Colombia.

Magister en Educación, Licenciada en educación preescolar. Docente universitaria en el área de pedagogía y arte en las licenciaturas de educación preescolar, educación física y educación artística. Experta en didácticas de la educación. Conferencista y tallerista en eventos académicos para la primera infancia. Obtuvo la distinción "Maestro Huella" del programa de Licenciatura en Educación Artística- Universidad de San Buenaventura-Medellín 2015, y la condecoración "Medalla a la Valentía ciudad de Medellín"-Decreto 0470 de 2019. Compositora de música infantil y directora del grupo musical Colombia de Colores. Asesora nacional en temas de lenguajes expresivos y resiliencia familiar para el Ministerio de Educación Nacional (MEN) de Colombia, el Instituto Colombiano de Bienestar Familiar (ICBF) y la Organización Internacional para las Migraciones (OIM).

Ter a mi profesora por una pantalla no es igual a tenerla a mi
lado en la escuela.

Esa fue la primera sensación que expresaron mis estudiantes cuando iniciamos el trabajo durante la cuarentena.

Luego de pasar por el acomodo a las nuevas formas de comunicación y de superar la realidad cruda de que muchos de mis estudiantes no contaban con las facilidades para acceder a los encuentros virtuales, empezamos el día a día de trabajo en casa, con apoyo virtual. Claro, entre las exclamaciones de añoranza por la escuela y las preguntas de cuándo se volvería a ella.

—Profe, ¿así está bien? —-me decía una de las niñas al describirme su tarea hecha, por llamada de voz.

-No puedo ver tu cuaderno, pero estoy segura, con lo que me cuentas, que has logrado hacerla bien.

Ambas reímos. 
Descubrí que, a pesar de las posibilidades tecnológicas para facilitar el aprendizaje, la labor humana del maestro no es reemplazable. Así, además del desarrollo de las temáticas o contenidos sustentados con fotos, videos o textos escritos, han sido fundamentales el diálogo, la empatía, la creatividad y la alegría.

Reafirmé que los encuentros sincrónicos, además de permitirnos observar videos, interactuar con juegos virtuales o seguir instrucciones de tutoriales o las propias, son también un momento para comprender y preguntar las razones del por qué aprendemos lo que aprendemos.

-Profe, muchas gracias, hoy hemos aprendido muchas cosas.

—Profe, ¿nos mandas por chat el video? Estaba muy interesante.

—Claro, me encanta que disfruten.

Entonces valoré mucho más eso de adaptar nuevas temáticas de aprendizaje con mirada resiliente en este tiempo de cambio. Así, la empatía y la escucha han sido primordiales para fortalecernos.

—Es que profe, no quiero hacer tantas guías.

—A ver, pega tu cuaderno a la cámara... ¡Sí, lo lograste!

—Profesora, tengo miedo de que mi mamá no se alivie...

-Profesora mi hijo está enfermo...

—Vamos, iánimo! Superaremos este tiempo difícil.

—Profe te extraño, extraño a mis compañeros, pero me encantan nuestras clases.

-Profe, en esta pandemia he aprendido a cuidarme del coronavirus, a que hay más de una forma de aprender y que al estar en casa aprendemos de nosotros mismos y también de los demás.

Me digo, entonces: "Sí. Con pantalla o sin pantalla de por medio, la sonrisa del maestro y su amor por su vocación no tiene remplazo".

\section{Cómo CITAR ESTe artículo}

* Cobaleda Estepa, Mónica Pilar. (2021, enero-febrero). Ningún lugar está lejos cuando se ama. Revista Digital Universitaria (RDU), 22(1). Dol: http://doi.org/10.22201/ cuaieed.16076079e.2021.22.1.12 